\title{
Low light intensity delays vegetative phase change
}

3 Mingli $\mathrm{Xu}^{\mathrm{a}, \mathrm{b}^{*}}$, Tieqiang $\mathrm{Hu}^{\mathrm{a}}$, and R. Scott Poethig ${ }^{\mathrm{a}}$

$4 \quad{ }^{a}$ Department of Biology, University of Pennsylvania, Philadelphia, PA, 19104-6018

$5{ }^{b}$ Department of Biological Sciences, University of South Carolina, Columbia, SC, 29208

$6 *$ Corresponding author:

$7 \quad$ Mingli $\mathrm{Xu}$

8 Department of Biological Sciences

9 University of South Carolina

10 Columbia, SC 29208

11 Email: minglixu@sc.edu

12 Phone: 803-576-8337

13 The author responsible for distribution of materials integral to the findings presented in

14 this article in accordance with the policy described in the Instructions for Authors

15 (www.plantphysiol.org) is: Mingli Xu (minglixu@sc.edu)

16 Author Contributions: M. X. and R.S.P. designed research; M.X, T.H., and R.S.P.

17 performed research; M. X. and R. S. P. analyzed data; and M.X. and R.S.P. wrote the 18 paper.

19 This work was supported by a grant from the National Institutes of Health (GM051893)

20 to R.S.P. and a grant from the National Science Foundation (IOS 1947274) to M.X. 


\section{Abstract}

22 Plants that develop under low intensity light (LL) often display a phenotype known as the

23 "shade tolerance syndrome (STS)". This syndrome is similar to the phenotype of plants in

24 the juvenile phase of shoot development, but the basis for this similarity is unknown. We

25 tested the hypothesis that the STS is regulated by the same mechanism that regulates the

26 juvenile vegetative phase by examining the effect of LL on rosette development in

27 Arabidopsis thaliana. We found that LL prolonged the juvenile vegetative phase and that

28 this was associated with an increase the expression of the master regulators of vegetative

29 phase change, miR156 and miR157, and a decrease in the expression of their SPL targets.

30 Exogenous sucrose partially corrected the effect of LL on seedling development and

31 miR156 expression. Our results suggest that the response of Arabidopsis to LL is

32 mediated by an increase in miR156/miR157 expression and by factors that repress SPL

33 gene expression independently of $\mathrm{miR} 156 / \mathrm{miR} 157$, and is caused in part by a decrease in

34 carbohydrate production. The effect of LL on vegetative phase change does not require

35 the photoreceptors and transcription factors responsible for the shade avoidance

36 syndrome, implying that light intensity and light quality regulate rosette development by

37 different pathways.

\section{Introduction}

39 Over the last 50 years, research on the response of plants to light has largely focused on

40 the effect of the presence vs. absence of light and the effect of light quality on early

41 seedling development (Smith, 1982; Chory, 1997; Roig-Villanova and Martinez-Garcia,

42 2016; Ballare and Pierik, 2017). Extensive research on the effect of red, far red, and blue

43 light on hypocotyl elongation in Arabidopsis has provided a deep understanding of the

44 molecular mechanism by which specific wavelengths of light regulate this developmental

45 process. In contrast, the effect of light intensity on plant development has received

46 relatively little attention, despite the fact that in nature plants can experience dramatic

47 variation in light intensity on both short (e.g. seconds or minutes) and long (hours,

48 months, years) time scales. 
Plants adapted for growth under low light intensity (LL), as well as shoots exposed to a prolonged period of LL, often exhibit a phenotype known as the shade tolerance syndrome (STS) (Valladares and Niinemets, 2008). This phenotype consists of a large number of physiological, morphological, and anatomical traits that optimize carbon gain; indeed, it is generally assumed that the primary, if not the only, function of the STS is to maximize photosynthesis under LL. However, some of the anatomical and morphological traits associated with the STS have no known function in photosynthesis (Valladares and Niinemets, 2008), raising the question of why the expression of these traits is associated with LL. Additionally, many of the anatomical/morphological features associated with the STS are distinct from, and in some cases opposite to, the traits that characterize the shade avoidance syndrome (SAS) (Valladares and Niinemets, 2008; Ballare and Pierik, 2017), a phenotype generated by a low R:FR light ratio or exposure to FR light near the end of the day. This is significant because in nature LL is typically caused by the presence of surrounding plants, which both decrease light intensity and decrease the R:FR ratio by absorbing red light during photosynthesis (Chory, 1997). This suggests that plants respond to LL and a decreased R:FR ratio by different mechanisms, and are able to "choose" the mechanism that is appropriate for the specific light conditions in which they find themselves.

It has been recognized for over a hundred years that leaves grown in LL resemble leaves produced during the juvenile phase of shoot development (Nordhausen, 1912; Schramm, 1912; Njoku, 1956). However, the basis for this similarity is unknown. One possibility is that the LL delays the juvenile-to-adult transition (vegetative phase change) or reactivates the juvenile vegetative phase in adult plants. An alternative possibility is that low light intensity affects some of the traits associated with the juvenile phase, without actually affecting the timing of vegetative phase change (Jones, 1995, 1999). Both hypotheses imply that the STS is regulated in whole or in part by the vegetative phase change pathway, and recent evidence that juvenile leaves are photosynthetically more efficient under low light intensity than adult leaves (Lawrence et al., 2020) provides intriguing support for this hypothesis. To investigate the role of the vegetative phase change pathway in the STS, we characterized the effect of LL on vegetative phase change in Arabidopsis. 
Vegetative phase change is regulated by a decline in the level of the related miRNAs, miR156/157, and the resulting increase in the expression of their targets, SQUAMOSA PROMOTER BINDING PROTEIN-LIKE (SPL) transcription factors (Wu and Poethig, 2006; Chuck et al., 2007; Wu et al., 2009). In Arabidopsis, miR156/157 directly regulate 10 SPL genes (Rhoades et al., 2002; Xu et al., 2016; He et al., 2018). These $S P L$ genes are responsible many aspects of adult shoot development, including adult leaf morphology, abaxial trichome production, reduced branching, a low propensity for adventitious root initiation and shoot regeneration, low anthocyanin production, decreased insect resistance, and increased thermosensitivity (Chuck et al., 2007; Schwarz et al., 2008; Wang et al., 2009; Wu et al., 2009; Yamaguchi et al., 2009; Yu et al., 2010; Gou et al., 2011; Padmanabhan et al., 2013; Stief et al., 2014; Zhang et al., 2015; Xu et al., 2016; Mao et al., 2017; Nguyen et al., 2017). produced by MIR156A and MIR156C (He et al., 2018). The down-regulation of these genes in successive rosette leaves is largely dependent on changes in their chromatin structure (Pico et al., 2015; Xu et al., 2016; Xu et al., 2018). Early in shoot development, MIR156A/MIR156C contain elevated levels of the active histone modification, H3K27ac (Xu et al., 2016), as well as high levels of H2A.Z, which facilitates the deposition of the active histone modification, $\mathrm{H} 3 \mathrm{~K} 4 \mathrm{me} 3$ (Xu et al., 2018). The subsequent repression of these genes is mediated by the deposition of $\mathrm{H} 3 \mathrm{~K} 27 \mathrm{me} 3$, in a process modulated by PRC1 (Pico et al., 2015), PRC2 (Xu et al., 2016), and the chromatin remodelers PICKLE (Xu et al., 2016) and BRAHMA (Xu et al., 2016). In addition to being posttranscriptionally repressed by miR156/157, the expression of $S P L$ genes is regulated by

103 several processes that operate independently of miR $156 / 157$, including H2A monoubiquitination (H2Aub) by AtRING1A/AtRING1B (Kim et al., 2015; Li et al., 2017), histone acetylation by SAGA-like histone acetyletransferase (HAG1) (Kim et al., 106 2015), and O-linked N-acetyleglucosamine modification of SPL proteins(Xu et al., 2017). 107 However, it is currently unknown if these modifications control the temporal and spatial 108 pattern of $S P L$ gene expression. 
Most of the research on the response of Arabidopsis to shade has focused on the mechanism of the SAS (Casal, 2013; Roig-Villanova and Martinez-Garcia, 2016; Ballare and Pierik, 2017). As noted above, this syndrome is produced by exposure to FR-

112 enriched light and a decrease in the intensity of blue light, leading to an increase in the

113 expression of the transcription factors PIF4, 5 and 7, the primary mediators of this

114 syndrome. It has been suggested that some aspects of the SAS are mediated by the $115 \mathrm{miR} 156 /$ SPL pathway based on the observation that miR156 levels decline by $80 \%$ while 116 SPL transcript levels increase up to 4-fold when plants are briefly exposed to FR light at 117 the end of the day (Xie et al., 2017). However this result has yet to be reconciled with the 118 observation that the primary sources of miR156 in Arabidopsis-MIR156A and $119 M I R 156 C$ - are not targets of the PIF transcription factors that mediate this EOD FR 120 response (Xie et al., 2017).

Here, we show that the juvenile-to-adult transition in Arabidopsis is delayed by

$122 \mathrm{LL}$, and that this response is mediated by both an increase in the level of $\mathrm{miR} 156 / \mathrm{miR} 157$,

123 and by a miR156-independent decrease in the level of SPL transcription factors.

124 Phytochrome- and cryptochrome-mediated signaling are not required for this response, 125 suggesting that the response of plants to light quality and their response to LL are mediated by different regulatory pathways. Along with the evidence that juvenile leaves are photosynthetically more efficient under LL than adult leaves (Lawrence et al., 2020),

128 these results suggest that the STS is under the regulation of the miR156/SPL vegetative 129 phase change pathway.

\section{Results}

131 Vegetative phase change is delayed by LL. To study the role of light intensity in 132 vegetative phase change without the complicating effect of a difference in flowering time, 133 we grew wild-type Col in short days under HL $\left(180 \mu \mathrm{mol} \mathrm{m}^{-2} \mathrm{~s}^{-1}\right)$ and LL $\left(62 \mu \mathrm{mol} \mathrm{m}^{-2} \mathrm{~s}^{-}\right.$

$134{ }^{1}$ ) conditions. This was accomplished by varying the number of fluorescent light bulbs in 135 otherwise identical growth chambers. Plants grown in LL were lighter green and slower 136 to develop than plants grown in HL (Fig. 1A, B), and their leaves were rounder and less 137 serrated than HL plants (Fig. 1C). Additionally, abaxial trichome production was 
138 significantly delayed in LL plants compared to plants grown in HL (Fig. 1C). These

139 results demonstrate that LL delays vegetative phase change.

To determine if the effect of light intensity on vegetative phase change is attributable to changes in the level of miR156/157, we measured the abundance of these

142 miRNAs in plants grown in short days (SD) under HL and LL. Because plants grow more 143 slowly in LL (Fig. 1B), we sampled shoot apices according to their developmental stage.

144 Samples were collected when leaves 1, 3, 5, 7, or 9 were $1 \mathrm{~mm}$ in length, and consisted of 145 this leaf primordium and all younger leaf primordia and the shoot apical meristem (L1+, $146 \mathrm{~L} 3+, \mathrm{L} 5+, \mathrm{L} 7+$ and L9+).

The temporal pattern of miR156 expression was similar in HL and LL, but the amount of miR156 in LL shoot apices was significantly higher than the amount of miR156 in HL apices at every stage of development (Fig. 1D). There was no significant difference in the abundance of miR157 in L1+ apices grown in LL and HL. In HL, the abundance of miR157 began to decline at L3+, whereas in LL it began to decline at L5+

152 (Fig. 1E). This slight delay in the down-regulation of miR157 relative to miR156 suggests that light intensity regulates the expression of miR156 and miR157 by different mechanisms. We then analyzed the effect of LL on the primary transcripts of MIR156A and MIR156C, the major sources of miR156 in Arabidopsis (He et al., 2018). Both transcripts were present at significantly higher levels at early stages of development (L1+, L3+, L5+) in LL- than in HL-grown plants (Fig. 1F and G), but declined to the same

158 level in older (L9+) plants. This result is consistent with the expression pattern of the 159 mature miR156 transcript, and suggests that these genes are primarily responsible for this 160 expression pattern. Consistent with the elevated levels of miR156, the SPL9, SPL13, and 161 SPL15 transcripts were less abundant in LL than in HL plants (Fig.1H and Fig. S1A). phase change under LL, we compared the phenotype of stocks deficient for miR156 164 (mir156a mir156c) or miR157 (mir157a mir157c), and stocks deficient for both of these 165 miRNAs (mir156a mir156c mir157a mir157c and 35S::MIM156) under HL and LL. 166 Abaxial trichome production was significantly delayed by LL in both wild-type Col and 
in the mir156a mir156c and mir157a mir157c double mutants. However, LL had a slightly smaller effect on abaxial trichome production in these mutants than in Col, and had no significant effect on abaxial trichome production in the mir156a mir156c mir157a mir 157c quadruple mutant or in 35S::MIM156 (Fig. 1I). These results demonstrate that miR156 and miR157 both contribute to the effect of LL on abaxial trichome production.

A miR156-independent pathway is involved in the $L L$ response. Although LL did not affect abaxial trichome production in the mir156a mir156c mir157a mir 157c and 35S::MIM156 lines (Fig. 1I), it did have a significant effect on leaf morphology in these miR156/157 deficient lines (Fig. 2A; Fig. S1B). In Arabidopsis, juvenile leaves have smaller angle between the petiole and the leaf blade than adult leaves (Yang et al., 2011; He et al., 2018). We found that LL significantly decreased the leaf blade: petiole angle of leaves $1 \& 2$ in both $\mathrm{Col}$ and in mutants deficient for miR156/157 (Fig. 2B). This result demonstrates that some of the effects of LL on leaf morphology do not require $\operatorname{miR} 156 / 157$.

To determine if the effect of LL on leaf morphology might be mediated by a miR156/157-independent effect of LL on SPL gene expression, we measured the abundance of the SPL9, SPL13 and SPL15 transcripts in Col and 35S::MIM156 seedlings under HL and LL (Fig. 2C). As expected (He et al., 2018), under HL all three transcripts were elevated in $35 S:: M I M 156$ seedlings relative to Col. LL reduced the expression of all three transcripts in both $\mathrm{Col}$ and $35 S:: M I M 156$ plants, but appeared to have a slightly bigger relative effect on SPL9 and SPL13 in Col than in 35S::MIM156, which is consistent with the elevated level of miR156 in LL Col plants .

miR156 represses SPL gene expression primarily at a translational level (He et al., 2018). Therefore, to obtain a more accurate picture of the relative importance of miR156dependent vs. miR156-independent regulation of SPL activity, we examined the effect of light intensity on the expression of miR156-sensitive and miR156-resistant pSPL13::SPL13-GUS translational reporters. LL nearly completely repressed the expression of the miR156-sensitive pSPL13::SPL13-GUS reporter, and reduced the expression of the miR156-resistant pSPL13::rSPL13-GUS to about 0.4 of the level in HL 
plants (Fig. 2C and D). These results demonstrate that light intensity regulates $S P L$ expression though both miR156-dependent and miR156-independent pathways.

The response to light intensity is partially mediated by carbohydrate. Mutations in the chlorophyll oxygenase gene, CHLORINA1 (CH1) (Oster et al., 2000), produce yellow-green plants that undergo delayed vegetative phase change (Yang et al., 2013), and thus resemble wild-type plants grown in LL. Wild-type plants grown in LL have about $60 \%$ of the amount of chlorophyll present in HL plants (Fig. 3A), whereas the chl4 mutant has about $30 \%$ of the wild-type level chlorophyll (Fig. 3B). Previous work has suggested that ch1-4 delays vegetative phase change because it reduces sugar production (Yang et al., 2013). To determine if the effect of LL on vegetative phase change is attributable to a reduction in the amount of sugar, we grew Col in HL and LL on media containing different concentrations of sucrose. $1 \%$ and $2 \%$ sucrose partially corrected the effect of LL on seedling growth, and 3\% sucrose did not produce further changes (Fig. 3C). We then measured the abundance of miR156 and miR157 in Col grown in HL and LL in the absence or presence of $2 \%$ sucrose. Plants grown in LL had 1.8 times as much miR156 and 1.2 times as much miR157 as developmentally comparable plants grown in HL. 2\% sucrose reduced the amount of miR156/miR157 in both HL and LL plants, but had a slightly greater effect on the level of these miRNAs in LL plants than in HL plants (Fig. 3D). We also examined the effect of $2 \%$ sucrose on the primary transcripts of MIR156A and MIR156C (Fig. 3E). Consistent with its effect on miR156, sucrose reduced the level of pri-miR156a and pri-miR156c more in LL plants than in HL plants (Fig. 3E). These results suggest that the effect of LL on the expression of miR156/miR157 is partially explained by the effect of LL on carbohydrate production.

\section{Light intensity probably regulates miR156 expression independently of H3K27me3.} Under HL, the down-regulation of MIR156A and MIR156C is mediated by the deposition of H3K27me3 at these loci (Pico et al., 2015; Xu et al., 2016). To determine if light intensity affects this process, we used chromatin immunoprecipitation (ChIP) to measure the level of H3K27me3 at MIR156A/MIR156C in HL and LL plants. The level of H3K27me3 at MIR156A/MIR156C was significantly lower in 2-week old LL plants than in 2-week old HL plants (Fig. 4A and B). However, in the case of MIR156A, this is 
226 probably explained by developmental delay caused by LL because 3-week old LL

227 plants — which were at the same developmental stage as 2-week old HL plants — had

228 nearly the same level of H3K27me3 at MIR156A as HL plants (Fig. 4A). In contrast, 3-

229 week old LL plants had significantly less H3K27me3 at MIR156C than 2-week old HL

230 plants (Fig. 4B). Thus, light intensity has a more significant effect on the deposition of

$231 \mathrm{H} 3 \mathrm{~K} 27 \mathrm{me} 3$ at $M I R 156 C$ than at MIR156A. To determine if light intensity modulates the

232 deposition of $\mathrm{H} 3 \mathrm{~K} 27 \mathrm{me} 3$ by affecting carbohydrate production, we used ChIP to measure

233 the level of H3K27me3 at MIR156A/MIR156C in two-week old plants growing in LL

234 with or without sucrose. Sucrose significantly elevated the level of H3K27me3 at

$235 M I R 156 A$ (Fig. 4C) but had no effect on the level of H3K27me3 at MIR156C (Fig. 4D).

236 In aggregate, these results indicate that LL and sugar can affect the level of H3K27me3 at

237 MIR156A or MIR 156C in ways that are consistent with the effect of these factors on the

238 expression of these genes. However, the biological significance of these results is unclear

239 because LL and sugar had different effects on the deposition of H3K27me3 at MIR 156A

240 and MIR 156C, even though these factors affected the expression of these genes in the

241 same way.

We next asked if the effect of LL on vegetative phase change requires H3K27me3.

243 This repressive histone modification is deposited on target chromatin by the activity of

244 Polycomb Repressive Complex 2 (PRC2) (Hennig and Derkacheva, 2009, 2009; Ito and

245 Sun, 2009, 2009; Bouyer et al., 2011, 2011), one component of which is the histone

246 methyl transferase, SWINGER (SWN) (Zhou et al., 2018; Shu et al., 2019). The CHD3-

247 like chromatin remodeler, PICKLE (PKL), also promotes the deposition of H3K27me3,

248 although the mechanism by which it does this is still unknown (Zhang et al., 2008; Zhang

249 et al., 2012; Xu et al., 2016). Plants mutant for both swn and pkl have reduced levels of

$250 \mathrm{H} 3 \mathrm{~K} 27 \mathrm{me} 3$ at MIR156A/MIR156C and display elevated expression of both genes (Xu et

251 al., 2016). To determine if changes in H3K27me3 are responsible for the effect of light

252 intensity on vegetative phase change, we compared the phenotype of $s w n-3$ pkl-10

253 mutants under HL and LL. Previously we reported that under HL swn-3, pkl-10, and the

254 swn-3 pkl-10 double mutant undergo delayed vegetative phase change (Xu et al., 2016),

255 and we were able to replicate this result (Fig. 4E). We also found that LL further delayed

256 vegetative phase change in these mutants. This was particularly dramatic in the case of 
swn-3 pkl-10. In HL the appearance of abaxial trichomes was delayed by 5 leaves in swn3 pkl-10 (19.4 \pm 0.3$)$ compared to $\mathrm{Col}(7.8 \pm 0.2)$; however, in LL, swn-3 pkl-10 produced abaxial trichomes over 37 leaves later than Col (51.0 \pm 0.9 vs. $13.1 \pm 0.3)$ (Fig. 4E). This result demonstrates that a reduction in $\mathrm{H} 3 \mathrm{~K} 27 \mathrm{me} 3$ makes plants hypersensitive to the effect of LL, but also suggests that effect of LL on vegetative phase change may not be mediated a LL-induced reduction in H3K27me3 because swn-3 pkl-10 already has low levels of H3K27me3 at MIR156A and MIR156C (Xu et al., 2016).

H3K27me3 is usually deposited at a locus over several days or weeks (Jiang et al., 2008; Angel et al., 2011; Coustham et al., 2012; Yang et al., 2014; Xu et al., 2016). We reasoned that if LL de-represses MIR156A/MIR156C by reducing the deposition of $\mathrm{H} 3 \mathrm{~K} 27 \mathrm{me} 3$, is it unlikely that a brief exposure to LL would cause a significant increase in the expression of these genes. To test this hypothesis, we grew $\mathrm{Col}$ in HL for 7 days and then compared the abundance of pri-miR156a and pri-mirR156c in the shoot apices of plants grown in HL for an additional 24 hours to plants transferred to LL for 24 hours.

271 Plants grown in HL for an additional 24 hrs had less pri-miR156a and pri-miR156c than

272 7-day old HL plants, which is expected because the expression of these transcripts

273 declines early in shoot development. In contrast, plants transferred to LL for $24 \mathrm{hrs} \mathrm{had}$

274 significantly more pri-miR156a and pri-miR156c than HL plants (Fig. 4F). Thus, LL has

275 a relatively rapid effect on the transcription of MIR156A/MIR156C, suggesting that this

276 effect is unlikely to be due to a decrease in H3K27me3 deposition.

The response to low light intensity is not mediated by phytochrome or cryptochrome signaling. It has been reported that the SAS is regulated in part by a decrease in expression of miR156, mediated by exposure to FR light at the end of the day (Xie et al., 2017). We therefore decided to investigate if the R:FR and blue light signaling pathways contribute to the response of plants to LL. In Arabidopsis, the main photoreceptors for R and FR light are phyA and phyB, and the main blue light photoreceptors are CRY1 and CRY2 (Casal, 2013). To determine if these photoreceptors are required for the response to LL, we examined the phenotype of plants deficient for CRY1 and CRY2 (hy4-B104 cry2-1) and plants deficient for PHYA and PHYB (phya-211 phyb-9) (Fig. 5A). The vegetative morphology, as well as the timing of abaxial trichome production, in the cryl 
cry2 double mutant was essentially identical to WT under both HL and LL conditions

288 (Fig. 5A). Consistent with previous reports (Reed et al., 1994; Devlin et al., 1996), under

289 HL phya phyb double mutants were light green, and had an elongated hypocotyl,

290 elongated internodes, small narrow leaves with elongated petioles, and flowered much

291 earlier than WT. These double mutants also produced abaxial trichomes significantly

292 earlier than WT plants under HL (Fig. 5A). phya phyb mutants had a similar if not

293 identical morphology under LL, but produced abaxial trichomes significantly later under

294 LL than under HL. However, the relative delay in abaxial trichome production in phya

295 phyb mutants under LL vs HL was slightly less than in WT plants. These results indicate

296 that CRY1 and CRY2 play no significant role in the response of plants to LL, and also

297 suggest that PHYA and PHYB may little or no role in this response.

To further explore the role of blue and red light in the STS, we examined the effect of LL on genes that mediate the effect of these stimuli. Red and blue light control plant growth by regulating the expression of a family of basic helix-loop-helix (bHLH) transcription factors known as PHYTOCHROME INTERACTING FACTORS (PIF) (Pedmale et al., 2016). PIF proteins accumulate in the presence of a low R:FR ratio and low intensity blue light, and promote the expression of genes that generate the SAS. Plants mutant for pif4 and pif5, as well as the pif1 pif3 pif4 pif5 quadruple mutant (pifq), do not display the SAS under low R:FR light or low intensity blue light, and resemble plants grown in HL (Leivar et al., 2012). If PIF proteins promote the STS as well as the SAS, the expectation is that that these proteins will be over-expressed under low light intensity and that loss of PIF gene expression will accelerate the onset of the adult phase.

To test these hypotheses, we first examined the effect of light intensity on the expression of PIF5 in seedlings and rosette leaves. Consistent with previous observations (Pedmale et al., 2016), the PIF5::GUS transcriptional reporter was highly expressed in the hypocotyl, shoot apex and cotyledons of seedlings germinated in HL for 4 days and transferred to the dark for 2 days, but was only expressed in the shoot apex of

314 seedlings grown continuously in HL (Fig. 5B); thus, PIF5::GUS expression in the

315 hypocotyl is repressed by HL. In 2-week old plants grown continuously in HL,

316 PIF5::GUS was strongly expressed in young leaf primordia but was restricted to the 
317 vascular tissue of fully expanded leaves. It had a similar expression pattern in 3-week old

318 plants grown in LL, which were developmentally comparable to the 2-week old HL

319 plants (Fig. 5B). MUG assays revealed no significant difference in the amount of GUS

320 activity in the shoot apex of plants grown in HL and LL (Fig. 5C). Therefore--in contrast

321 to its expression in the hypocotyl--PIF5 expression in rosette leaves is insensitive to light

322 intensity. We next examined the effect of the pifq mutant on abaxial trichome production

323 under HL and LL conditions. There was no significant difference in the timing of abaxial

324 trichome production in wild type and pifa mutant in HL; however abaxial trichome

325 production was delayed more significantly in LL in the pifq mutant than in Col (Fig. 5D).

326 This latter result implies that PIF proteins repress the response of plants to LL, which is

327 the opposite of their function in the response to low R:FR light (i.e the SAS), which they

328 promote. Together, these results indicate that LL delays vegetative phase change by a

329 mechanism that is distinct from the mechanism involved in the SAS.

\section{Discussion}

331 The STS is typically considered to consist of a set of traits that enable a plant to fix 332 carbon above the photosynthetic compensation point under low light intensity (5); in 333 other words, it is viewed as a physiological adaptation to low light intensity. This begs

334 the question of how LL promotes the expression of these traits, and why the STS includes 335 traits that have no obvious connection to photosynthesis. Our results suggest that the 336 answer to these questions lies in the effect of LL on the expression of genes that regulate 337 vegetative phase change, specifically, miR156/miR157, and their targets, the SPL family 338 of transcription factors. This conclusion is supported by the observation that juvenile 339 leaves of Arabidopsis, maize, and poplar are photosynthetically more efficient under LL 340 than adult leaves (Lawrence et al., 2020) and by the results of this study.

341 We found that LL prolongs the duration of the juvenile phase and that it does so by both 342 increasing the abundance of miR156 and by decreasing the transcription of the SPL genes 343 regulated by miR156. These effects appear to be mediated by a reduction in

344 photosynthesis, as well as by other unknown factors. Importantly, the effect of LL on

345 vegetative phase change does not require the photoreceptors that mediate the response of 
Arabidopsis to red and blue light, specifically, phyA, phyB, CRY1 and CRY2, or the PIF transcriptions factors that mediate the effects of these photoreceptors. This supports the conclusion that LL regulates vegetative phase change by a different mechanism, or set of mechanisms, than the mechanism responsible for the SAS. Further supporting this conclusion, the traits associated with the SAS are opposite to the traits associated with the STS. Specifically, in Arabidopsis, exposure to a low R:FR ratio or end-of-day FR light produces elongated internodes, and light green elongated leaves with long petioles, and accelerated abaxial trichome production, whereas LL produces normal length internodes, and rounded, dark green leaves with normal length petioles and delayed abaxial trichome production.

Evidence that LL operates through both miR156-dependent and miR156independent mechanisms is provided by the effect of LL on plants deficient for miR156. Specifically, we found that miR156 is essential for the effect of LL on abaxial trichome production, but is not essential for its effect on leaf shape. We also found that the expression the direct targets of miR156 is reduced by LL even in a genetic background with little or no functional miR156 and miR157. Finally, we found that LL reduces the expression of a miR156-insensitive translational reporter for SPL13. Together, these observations suggest that specific phenotype of plants grown in LL may depend on the SPL genes that regulate particular traits and on the relative importance of posttranscriptional (i.e. miR156-dependent) vs. transcriptional regulation for the expression of these SPL genes. This scenario could explain why the phenotype of plants growing under low light intensity is similar but not necessarily identical to the phenotype of juvenile shoots growing under high light intensity (Jones, 1995).

The observation that exogenous sucrose partially corrects the effect of LL on the expression of MIR156A is consistent with previous studies demonstrating that sugar accelerates vegetative phase change (Yang et al., 2013; Yu et al., 2013), and supports the hypothesis that LL delays vegetative phase change through its effect on photosynthesis. However, this is not the only explanation for the effect of LL on vegetative phase change because sugar did not correct the LL-induced increase in the expression of MIR156C or the LL-induced reduction in $\mathrm{H} 3 \mathrm{~K} 27 \mathrm{me} 3$ at this gene. Although this decrease in 
376

377

378

379

380

381

H3K27me3 may contribute to the increase in MIR156C expression, it is unlikely to be the only factor involved in this response because MIR156C expression increases relatively quickly in response to LL. Together, these results suggest that LL regulates the expression of miR 156 by reducing photosynthesis, and by several light-sensitive processes or pathways that operate independently of photosynthesis.

The observation that shade intolerant species are able to display features characteristic of the STS when grown in LL suggests that the genes responsible for the STS are not unique to shade tolerant species. Interspecific comparisons of plants with strongly differentiated juvenile and adult phases have suggested that the morphology of juvenile shoots is an adaptation to LL environments (Day, 1998), and this is supported by studies in species with less highly differentiated juvenile and adult phases (Lusk, 2004; Lusk et al., 2008). Additional support for this conclusion comes from the observation that the photosynthetic properties of juvenile leaves in English ivy (Hedera helix) resemble those of leaves adapted for growth in LL (Bauer and Bauer, 1980), and from a recent study demonstrating that juvenile leaves, as well as leaves over-expressing miR156, have a significantly higher maximum rate of photosynthesis under LL than adult leaves and that the rate of photosynthesis in these leaves is less sensitive to LL than the rate of photosynthesis in adult leaves (Lawrence et al., 2020). These studies, and the results presented here, suggest that the juvenile phase is naturally adapted for LL conditions, and further suggest that the STS is regulated by the vegetative phase change pathway.

\section{Materials and Methods}

Plant Material and Growth Conditions. All mutants used in this study were in a Columbia background. mir156a-2, mir156c-1, mir157a-1, mir157c-1, 35S:MIM156, chlorina 1-4, swn-3, pkl-10, and swn3 pkl-10 have been described previously (Wang et al., 2009; Yang et al., 2013; Xu et al., 2016; He et al., 2018). Seeds of the phya-211 phyb-9 and cry 1 (hy4-B104) cry2-1 double mutants were provided by Dr. Meng Chen (U. of California, Riverside). The phyb-9 lines lack the mutation in the VENOSA-4 gene that is present in the original phyb-9 stock. The pifl-1 pif3-7 pif4-2 pif5-3 (pifq) quadruple mutant was obtained from the Arabidopsis Resource Center and the PIF5::GUS line was 
405

provided by Dr. Joanne Chory (Salk Institute, La Jolla, CA). Plants were grown in Conviron growth chambers in short days (10 hrs light: $14 \mathrm{hrs}$ dark) at $22^{\circ} \mathrm{C}$, with illumination provided by a combination of Sylvania warm white $(4000 \mathrm{~K})$ and Interlectric WS Gro-lite T8 fluorescent bulbs. High light conditions consisted of an overall intensity of $180 \mu \mathrm{mol} \mathrm{m}^{-2} \mathrm{~s}^{-1}\left[15.7 \mu \mathrm{mol} \mathrm{m} \mathrm{s}^{-2}\right.$ blue (450-550 nm), $59 \mu \mathrm{mol} \mathrm{m} \mathrm{m}^{-1}$ red (610-740 $\mathrm{nm}), 9.4 \mu \mathrm{mol} \mathrm{m} \mathrm{m}^{-2} \mathrm{~s}^{-1}$ far red (710-850 nm)]. Low light conditions consisted of an overall intensity of $62 \mu \mathrm{mol} \mathrm{m} \mathrm{s}^{-1}\left[5 \mu \mathrm{mol} \mathrm{m} \mathrm{s}^{-1}\right.$ blue (450-550 nm), $20 \mu \mathrm{mol} \mathrm{m} \mathrm{s}^{-1}$ red (610$740 \mathrm{~nm}), 3.75 \mu \mathrm{mol} \mathrm{m}^{-2} \mathrm{~s}^{-1}$ far red $\left.(710-850 \mathrm{~nm})\right]$. For sugar treatment, plants were grown in $1 / 2$ MS plates with or without $1 \%, 2 \%, 3 \%$ sucrose as indicated.

Quantitative RT-PCR. RNA for RT-qPCR analysis was isolated from shoot apices containing leaves less than $1 \mathrm{~mm}$ in length. HL or LL-grown plants were compared at the same developmental stage. For example, the SL1+ apices were harvested by removing the two cotyledons when leaf primordia 1 and 2 had just emerged. SL3+ apices were harvested when leaf primordium 3 was just visible, and the cotyledons and leaf 1 and 2 were removed. Total RNA was isolated using TRIzol method, followed by DNase treatment (Ambion) according to the manufacturer's instructions. The primers used for this study were the same as the primers in Xu et al. (2016).

Chlorophyll Concentration. Leaf punches were collected from the middle of lamina (leaf 3 or leaf 4 ) and ground in a mortar and pestle. The ground tissue was suspended in $80 \%$ acetone and centrifuged briefly. The optical density of the supernatant was measured at $645 \mathrm{~nm}$ and $663 \mathrm{~nm}$ using a spectrophotometer, and chlorophyll concentration was calculated as $\left.\left(\mathrm{OD}_{645} \times 20.2+\mathrm{OD}_{663} \times 8\right) / \mathrm{ml} \cdot \mathrm{cm}^{2}\right)$.

Chromatin Immunoprecipitation. Chromatin was isolated from Col plants at the same developmental stage and immunoprecipitated with antibodies to $\mathrm{H} 3$ or H3K27me3 as previously described (Xu et al., 2016). DNA sequences were analyzed by qPCR, using the primers for MIR156A and MIR156C described in (Xu et al., 2016).

ACKNOWLEDGEMENTS. We gratefully acknowledge helpful discussions with Dr. Meng Chen (U. of California, Riverside) and members of the Poethig laboratory. 
433

434

\section{References}

Angel A, Song J, Dean C, Howard M (2011) A Polycomb-based switch underlying quantitative epigenetic memory. Nature 476: 105-108

Ballare CL, Pierik R (2017) The shade-avoidance syndrome: multiple signals and ecological consequences. Plant Cell Environ 40: 2530-2543

Bauer H, Bauer U (1980) PHOTOSYNTHESIS IN LEAVES OF THE JUVENILE AND ADULT PHASE OF IVY (HEDERA-HELIX). Physiologia Plantarum 49: 366-372

\section{Bouyer D, Roudier F, Heese M, Andersen ED, Gey D, Nowack MK, Goodrich J,} Renou JP, Grini PE, Colot V, Schnittger A (2011) Polycomb repressive complex 2 controls the embryo-to-seedling phase transition. PLoS Genet 7: e1002014

\section{Bouyer D, Roudier F, Heese M, Andersen ED, Gey D, Nowack MK, Goodrich J,} Renou JP, Grini PE, Colot V, Schnittger A (2011) Polycomb repressive complex 2 controls the embryo-to-seedling phase transition. PLoS genetics 7: e1002014

Casal JJ (2013) Photoreceptor signaling networks in plant responses to shade. Annu Rev Plant Biol 64: 403-427

Chory J (1997) Light modulation of vegetative development. Plant Cell 9: 1225-1234

Chuck G, Cigan AM, Saeteurn K, Hake S (2007) The heterochronic maize mutant Corngrass 1 results from overexpression of a tandem microRNA. Nat Genet 39: 544-549

\section{Coustham V, Li P, Strange A, Lister C, Song J, Dean C (2012) Quantitative} modulation of polycomb silencing underlies natural variation in vernalization. Science 337: 584-587

Day JS (1998) Light conditions and the evolution of heteroblasty (and the divaricate form) in New Zealand. New Zealand Journal of Ecology 22: 43-54

Devlin PF, Halliday KJ, Harberd NP, Whitelam GC (1996) The rosette habit of Arabidopsis thaliana is dependent upon phytochrome action: novel phytochromes control internode elongation and flowering time. Plant J 10: 1127-1134 
Gou JY, Felippes FF, Liu CJ, Weigel D, Wang JW (2011) Negative regulation of anthocyanin biosynthesis in Arabidopsis by a miR156-targeted SPL transcription factor. Plant Cell 23: 1512-1522

\section{He J, Xu M, Willmann MR, McCormick K, Hu T, Yang L, Starker CG, Voytas DF,} Meyers BC, Poethig RS (2018) Threshold-dependent repression of SPL gene expression by miR156/miR157 controls vegetative phase change in Arabidopsis thaliana. PLoS Genet 14: e1007337

Hennig L, Derkacheva M (2009) Diversity of Polycomb group complexes in plants: same rules, different players? Trends Genet 25: 414-423

Hennig L, Derkacheva M (2009) Diversity of Polycomb group complexes in plants: same rules, different players? Trends in genetics : TIG 25: 414-423

Ito T, Sun B (2009) Epigenetic regulation of developmental timing in floral stem cells. Epigenetics : official journal of the DNA Methylation Society 4: 564-567

Ito T, Sun B (2009) Epigenetic regulation of developmental timing in floral stem cells. Epigenetics 4: 564-567

Jiang D, Wang Y, Wang Y, He Y (2008) Repression of FLOWERING LOCUS C and FLOWERING LOCUS T by the Arabidopsis Polycomb repressive complex 2 components. PLoS One 3: e3404

Jones CS (1995) Does shade prolong juvenile development? A morphological analysis of leaf shape changes in Cucurbita argyrosperma Subsp. Sororia (Cucurbitaceae). Amer. J. Bot. 82: 346-359

Jones CS (1999) An essay on juvenility, phase change, and heteroblasty in seed plants. Intl. J. Plant Sci. 160: S105-S111

Kim JY, Oh JE, Noh YS, Noh B (2015) Epigenetic control of juvenile-to-adult phase transition by the Arabidopsis SAGA-like complex. Plant J 83: 537-545

Lawrence EH, Springer CJ, Helliker BR, Poethig RS (2020) miR156-mediated changes in leaf composition lead to altered photosynthetic traits during vegetative phase change. New Phytol DOI: 10.1111/nph.17007

\section{Leivar P, Tepperman JM, Cohn MM, Monte E, Al-Sady B, Erickson E, Quail PH} (2012) Dynamic antagonism between phytochromes and PIF family basic helixloop-helix factors induces selective reciprocal responses to light and shade in a 
rapidly responsive transcriptional network in Arabidopsis. Plant Cell 24: 13981419

Li J, Wang Z, Hu Y, Cao Y, Ma L (2017) Polycomb Group Proteins RING1A and RING1B Regulate the Vegetative Phase Transition in Arabidopsis. Front Plant Sci 8: 867

Lusk CH, Falster DS, Jara-Vergara CK, Jimenez-Castillo M, Saldana-Mendoza A

Lusk CH (2004) Leaf area and growth of juvenile temperate evergreens in low light: species of contrasting shade tolerance change rank during ontogeny. Functional Ecology 18: 820-828 (2008) Ontogenetic variation in light requirements of juvenile rainforest evergreens. Functional Ecology 22: 454-459

\section{Mao YB, Liu YQ, Chen DY, Chen FY, Fang X, Hong GJ, Wang LJ, Wang JW,} Chen XY (2017) Jasmonate response decay and defense metabolite accumulation contributes to age-regulated dynamics of plant insect resistance. Nat. Commnun 8: 13925

Nguyen ST, Greaves T, McCurdy DW (2017) Heteroblastic Development of Transfer Cells Is Controlled by the microRNA miR156/SPL Module. Plant Physiol 173: 1676-1691

Njoku E (1956) Studies in the morphogenesis of leaves XI. The effect of light intensity on leaf shape in Ipomea caerulea. New Phytol. 55: 91-110

Nordhausen M (1912) Über Sonnen- und Schattenblåtter. II. . Ber dtsch bot Ges 30: 433-503

Oster U, Tanaka R, Tanaka A, Rudiger W (2000) Cloning and functional expression of the gene encoding the key enzyme for chlorophyll b biosynthesis (CAO) from Arabidopsis thaliana. The Plant journal : for cell and molecular biology 21: 305310

Padmanabhan MS, Ma S, Burch-Smith TM, Czymmek K, Huijser P, Dinesh-Kumar SP (2013) Novel positive regulatory role for the SPL6 transcription factor in the N TIR-NB-LRR receptor-mediated plant innate immunity. PLoS Pathog 9: e1003235 
Pedmale UV, Huang SS, Zander M, Cole BJ, Hetzel J, Ljung K, Reis PA, Sridevi P, Nito K, Nery JR, Ecker JR, Chory J (2016) Cryptochromes Interact Directly with PIFs to Control Plant Growth in Limiting Blue Light. Cell 164: 233-245

Pico S, Ortiz-Marchena MI, Merini W, Calonje M (2015) Deciphering the Role of POLYCOMB REPRESSIVE COMPLEX1 Variants in Regulating the Acquisition of Flowering Competence in Arabidopsis. Plant Physiol 168: 1286-1297

Reed JW, Nagatani A, Elich TD, Fagan M, Chory J (1994) Phytochrome A and Phytochrome B Have Overlapping but Distinct Functions in Arabidopsis Development. Plant Physiol 104: 1139-1149

Rhoades MW, Reinhart BJ, Lim LP, Burge CB, Bartel B, Bartel DP (2002) Prediction of plant microRNA targets. Cell 110: 513-520

Roig-Villanova I, Martinez-Garcia JF (2016) Plant Responses to Vegetation Proximity: A Whole Life Avoiding Shade. Front Plant Sci 7: 236

Schramm R (1912) Über die anatomischen Jugenformen der Blåtter einhheimischer Holzpflanzen. Flora (Jena) 104: 225-295

Schwarz S, Grande AV, Bujdoso N, Saedler H, Huijser P (2008) The microRNA regulated SBP-box genes SPL9 and SPL15 control shoot maturation in Arabidopsis. Plant Mol Biol 67: 183-195

Shu J, Chen C, Thapa RK, Bian S, Nguyen V, Yu K, Yuan ZC, Liu J, Kohalmi SE, Li C, Cui Y (2019) Genome-wide occupancy of histone H3K27 methyltransferases CURLY LEAF and SWINGER in Arabidopsis seedlings. Plant Direct 3: e00100

Smith H (1982) LIght quality, photoperception, and plant strategy. Ann Rev Plant Physiol 33: 481-518

Stief A, Altmann S, Hoffmann K, Pant BD, Scheible WR, Baurle I (2014) Arabidopsis miR156 Regulates Tolerance to Recurring Environmental Stress through SPL Transcription Factors. Plant Cell 26: 1792-1807

Valladares F, Niinemets U (2008) Shade tolerance, a key plant feature of complex nature and consequences. Ann Rev Ecol Syst 39: 237-257 
Wang J-W, Czech B, Weigel D (2009) miR156-regulated SPL transcription factors define an endogenous flowering pathway in Arabidopsis thaliana. Cell 138: 738749

Wu G, Park MY, Conway SR, Wang JW, Weigel D, Poethig RS (2009) The sequential action of miR156 and miR172 regulates developmental timing in Arabidopsis. Cell 138: 750-759

Wu G, Poethig RS (2006) Temporal regulation of shoot development in Arabidopsis thaliana by miR156 and its target SPL3. Development 133: 3539-3547

Xie Y, Liu Y, Wang H, Ma X, Wang B, Wu G, Wang H (2017) Phytochromeinteracting factors directly suppress MIR156 expression to enhance shadeavoidance syndrome in Arabidopsis. Nat Commun 8: 348

Xu M, Hu T, Smith MR, Poethig RS (2016) Epigenetic Regulation of Vegetative Phase Change in Arabidopsis. Plant Cell 28: 28-41

\section{Xu M, Hu T, Zhao J, Park MY, Earley KW, Wu G, Yang L, Poethig RS (2016)} Developmental Functions of miR156-Regulated SQUAMOSA PROMOTER BINDING PROTEIN-LIKE (SPL) Genes in Arabidopsis thaliana. PLoS Genet 12: e1006263

Xu M, Leichty AR, Hu T, Poethig RS (2018) H2A.Z promotes the transcription of MIR156A and MIR156C in Arabidopsis by facilitating the deposition of H3K4me3. Development 145

Xu SL, Chalkley RJ, Maynard JC, Wang W, Ni W, Jiang X, Shin K, Cheng L, Savage D, Huhmer AF, Burlingame AL, Wang ZY (2017) Proteomic analysis reveals O-GlcNAc modification on proteins with key regulatory functions in Arabidopsis. Proc Natl Acad Sci U S A 114: E1536-E1543

Xu Y, Guo C, Zhou B, Li C, Wang H, Zheng B, Ding H, Zhu Z, Peragine A, Cui Y, Poethig S, Wu G (2016) Regulation of Vegetative Phase Change by SWI2/SNF2 Chromatin Remodeling ATPase BRAHMA. Plant Physiol 172: 2416-2428 activator of LEAFY, FRUITFULL, and APETALA1. Dev Cell 17: 268-278 
Yang H, Howard M, Dean C (2014) Antagonistic roles for H3K36me3 and H3K27me3 in the cold-induced epigenetic switch at Arabidopsis FLC. Curr Biol 24: 17931797

Yang L, Conway SR, Poethig RS (2011) Vegetative phase change is mediated by a leafderived signal that represses the transcription of miR156. Development 138: 245 249

Yang L, Xu M, Koo Y, He J, Poethig RS (2013) Sugar promotes vegetative phase change in Arabidopsis thaliana by repressing the expression of MIR156A and MIR156C. eLife 2: e00260

Yu N, Cai WJ, Wang S, Shan CM, Wang LJ, Chen XY (2010) Temporal control of trichome distribution by microRNA156-targeted SPL genes in Arabidopsis thaliana. Plant Cell 22: 2322-2335

Yu S, Cao L, Zhou CM, Zhang TQ, Lian H, Sun Y, Wu J, Huang J, Wang G, Wang JW (2013) Sugar is an endogenous cue for juvenile-to-adult phase transition in plants. eLife 2: e00269

Zhang H, Bishop B, Ringenberg W, Muir WM, Ogas J (2012) The CHD3 remodeler PICKLE associates with genes enriched for trimethylation of histone H3 lysine 27. Plant physiology 159: 418-432

Zhang H, Rider SD, Jr., Henderson JT, Fountain M, Chuang K, Kandachar V, Simons A, Edenberg HJ, Romero-Severson J, Muir WM, Ogas J (2008) The CHD3 remodeler PICKLE promotes trimethylation of histone H3 lysine 27. J Biol Chem 283: 22637-22648

Zhang TQ, Lian H, Tang H, Dolezal K, Zhou CM, Yu S, Chen JH, Chen Q, Liu H, Ljung K, Wang JW (2015) An intrinsic microRNA timer regulates progressive decline in shoot regenerative capacity in plants. Plant Cell 27: 349-360

Zhou Y, Wang Y, Krause K, Yang T, Dongus JA, Zhang Y, Turck F (2018) Telobox motifs recruit CLF/SWN-PRC2 for H3K27me3 deposition via TRB factors in Arabidopsis. Nat Genet 50: 638-644 


\section{Figure Legends}

614 Figure 1. LL delays vegetative phase change via miR156/157. (A) Col plants grown

615 under HL (left) are greener and have more leaves than plants grown under LL (right). (B)

616 Rate of leaf initiation in Col grown in HL and LL. $\mathrm{n}=32$ for each condition.

$617 \mathrm{P}<0.001$, one-way ANOVA. (C) LL delays the production of rosette leaves with abaxial

618 trichomes in Col. Green = no abaxial trichomes; Black = abaxial trichomes. (D-G) RT-

619 qPCR of miR156 (D), miR157 (E), pri-miR156a (F), and pri-miR156c (G) in the shoot

620 apices of Col plants grown in HL and LL. Samples were harvested according to their

621 developmental stage. (H) RT-qPCR analysis of the transcripts of miR156/157-targeted

622 genes in $\mathrm{L} 3+$ shoot apices. In D-H, values are the mean $\pm \mathrm{SEM}$ from 3 biological

623 replicates. (I) The first leaf with abaxial trichomes in Col and mutant plants deficient for $624 \mathrm{miR} 156$, miR157, and miR156 \& miR157 under HL and LL conditions. $\mathrm{n}=20$ to 24 for 625 each genotype. ** denotes $\mathrm{p}<0.01$, and $* * *$ denotes $\mathrm{P}<0.001$, one-way ANOVA.

627 Figure 2. LL affects leaf morphology and SPL expression independently of miR156/157.

628 (A) The morphology of leaf 1 under HL and LL in wild-type Col, in mutants lacking $629 \mathrm{miR} 156$ and/or miR157, and in plants constitutively expressing a miR156/157 target site 630 mimic. (B) The petiole:blade angle of leaf 1\&2 under HL and LL in wild-type Col and in 631 genotypes deficient for miR156, miR157 and both miR156 and miR157. (C) The relative 632 amount of SPL9, SPL13 and SPL15 transcripts in Col and 35S::MIM156 plants grown in 633 HL and LL. Values are normalized to the transcript level in Col grown under HL. The 634 ratio of the transcript abundance in LL relative to HL in each genotype is indicated. (D) 635 MUG assays of GUS activity in transgenic plants expressing miR156-sensitive (left) and 636 miR156-resistant (right) genomic constructs of SPL13-GUS under HL and LL. Note the 637 difference in the scale of the $\mathrm{Y}$ axes. $* * * \mathrm{p}<0.001, * * \mathrm{p}<0.01, * \mathrm{p}<0.05$, one-

638 way ANOVA. RT-qPCR analyses and MUG assays are mean $\pm \mathrm{SEM}$ from 3 biological 639 replicates. 
642 Figure 3. Sucrose partially corrects the de-repression of miR156 in LL. (A and B)

643 Chlorophyll concentration in Col under HL and LL (A), and in Col and ch1-4 under HL

644 (B). Values are mean \pm SEM from 4 biological replicates. (C) Col seedlings grown under

645 HL and LL in the absence or presence of exogenous sucrose. (D) The effect of exogenous

646 sucrose on the abundance of miR156 and miR157 in Col seedlings grown in LL. Values

647 were normalized to the transcript leaves in Col under HL. The amount of transcript in LL

648 relative to HL is shown. (E) The effect of exogenous sucrose on the abundance of pri-

649 miR156a and pri-miR156c in Col seedlings grown in LL. Values were normalized to the

650 transcript leaves in Col under HL. The amount of transcript in LL relative to HL is

651 shown. $* * * p<0.001, * p<0.05$, one-way ANOVA. Values are mean \pm SEM from 3

652 biological replicates.

653 Figure 4. LL does not act by decreasing the deposition of $\mathrm{H} 3 \mathrm{~K} 27 \mathrm{me} 3$ at $M I R 156 \mathrm{~A}$ and

654 MIR156C. (A and B) Schematic diagram of the genomic structure of MIR156A and

655 MIR156C and ChIP-qPCR analysis of H3K27me3 at these loci in 2-week or 3-week old

656 Col plants grown in HL or LL. Black boxes represent exons, the grey box represents the

657 miR156 hairpin, and arrows indicate transcription start site. (C and D) ChIP-qPCR

658 analysis of $\mathrm{H} 3 \mathrm{~K} 27 \mathrm{me} 3$ at MIR156A (C) and MIR156C (D) in Col plants grown in LL

659 with or without sucrose. (E) The first leaf with abaxial trichomes in Col, swn-3, pkl-10,

660 and $s w n-3$ pkl-10 plants grown in HL and LL. $\mathrm{n}=20$ to 24 for each genotype. (F) RT-

661 qPCR analysis of the abundance of pri-miR156a and pri-miR156c transcripts in Col

662 seedlings 24 hours after the transfer from HL to LL. ${ }^{* * *} \mathrm{p}<0.001,{ }^{*} \mathrm{p}<0.05$, one-

663 way ANOVA. Values in A-D and F are mean \pm SEM from 3 biological replicates.

664 Figure 5. The red and blue light signaling pathways are not required for the effect of LL

665 on vegetative phase change. (A) The effect of HL and LL on the first leaf with abaxial

666 trichomes in $\mathrm{Col}$ and plants deficient for the red-light photoreceptors, phyA and phyB,

667 and the blue light photoreceptors, CRY1 and CRY2. (B) Expression of PIF5::PIF5-GUS

668 in seedlings and rosette leaves in HL and LL. (C) Quantitative MUG assay of

669 PIF5::PIF5-GUS activity in the HL and LL rosettes shown in (B). (D) First leaf with

670 abaxial trichome production in Col and pifq. ${ }^{* * *} \mathrm{p}<0.001,{ }^{*} \mathrm{p}<0.05$, one-way ANOVA. 
673 Figure S1. LL delays vegetative phase change. (A) RT-qPCR analysis of SPL9, SPL13, 674 and SPL15 transcripts in L5+ shoot apices from plants grown in HL and LL. ${ }^{*} \mathrm{p}<0.05$,

675 one-way ANOVA. Values are mean \pm SEM from 3 biological replicates. (B) The

676 morphology and pattern of abaxial trichome production in Col, mir156a mir156c,

677 mir157a mir157c, mir156a mir156c mir157a mir157c, and 35S::MIM156 plants grown in

678 HL and LL conditions. Grey = no abaxial trichomes. Black = abaxial trichomes.

679

680

681 


\section{Figure 1}

A

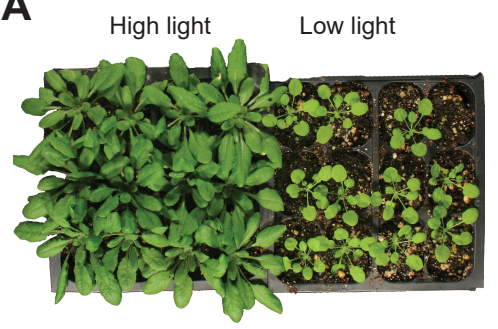

C

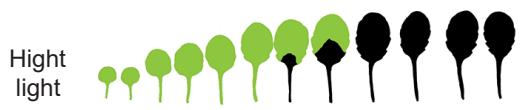

Low light

E

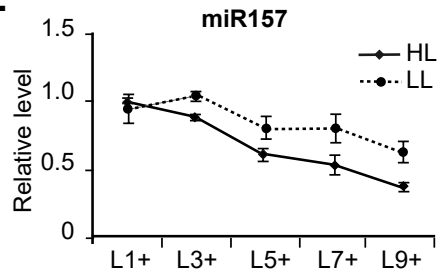

G

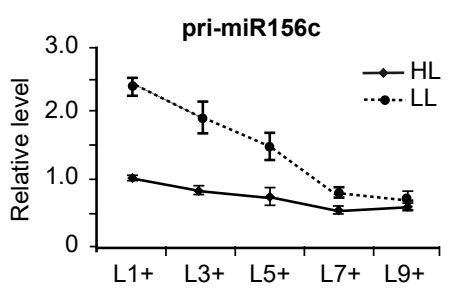

I

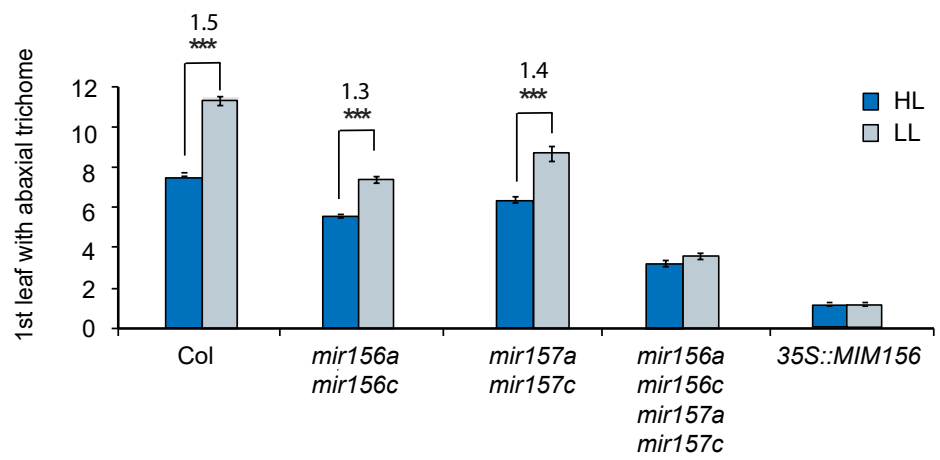

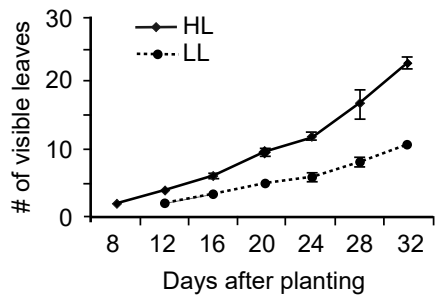

D

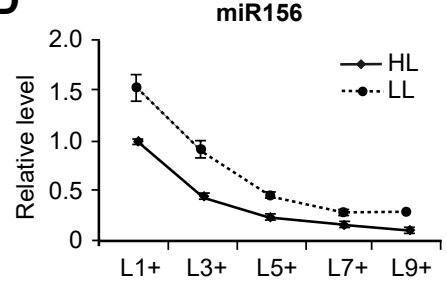

F

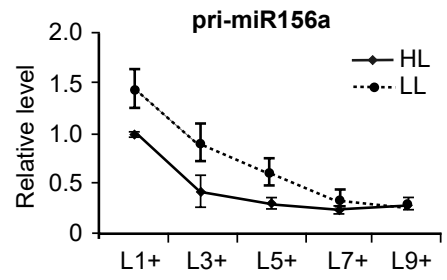

H

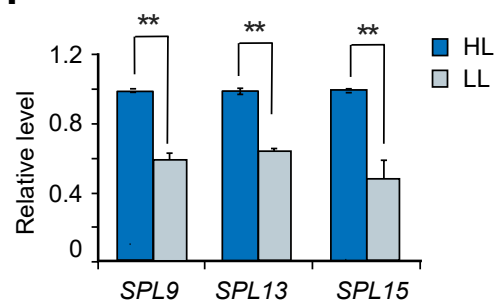


Figure 2

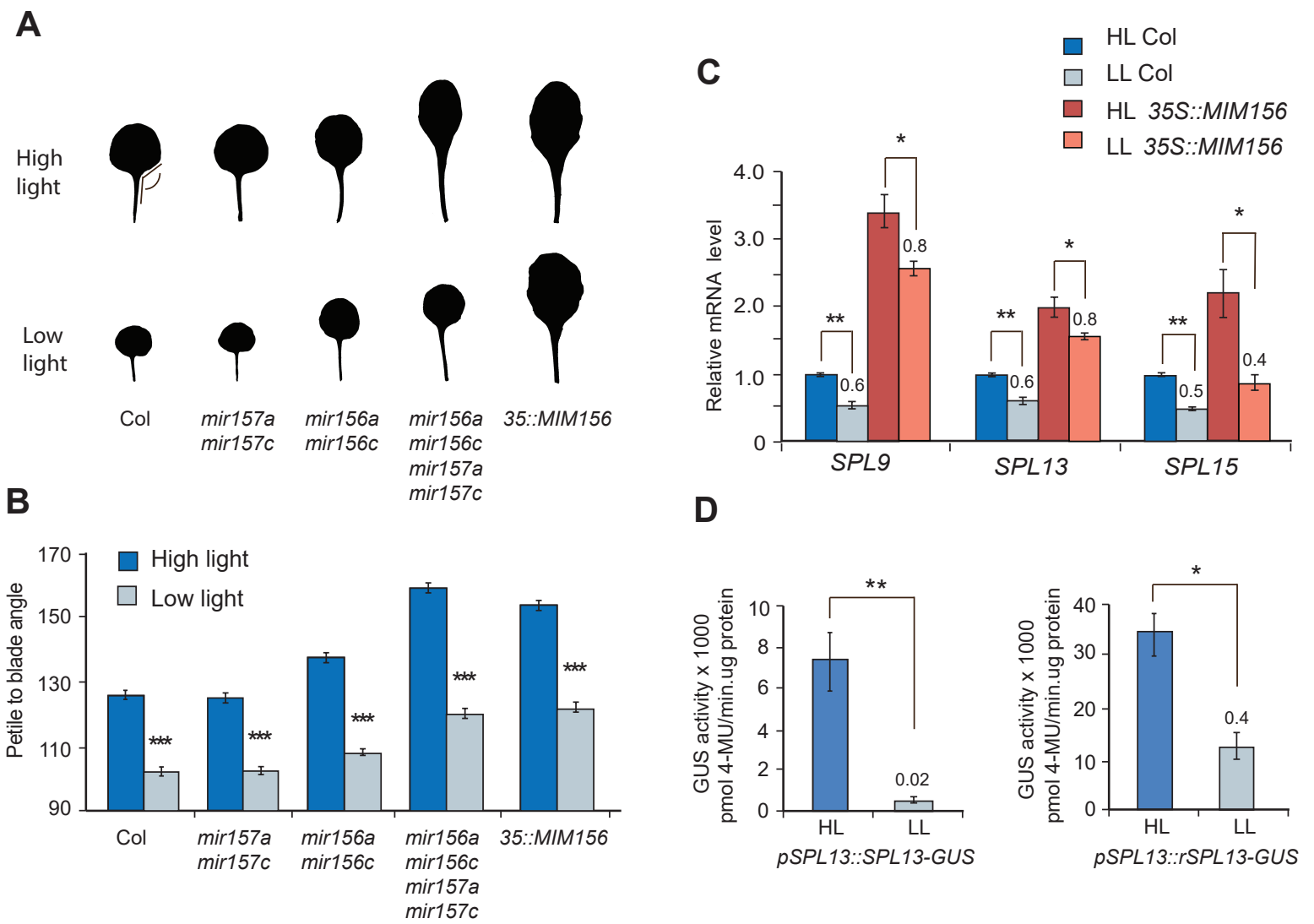


Figure 3

A

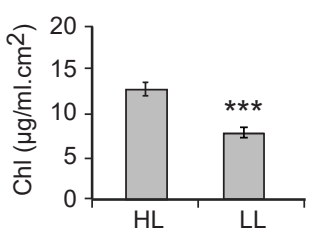

B

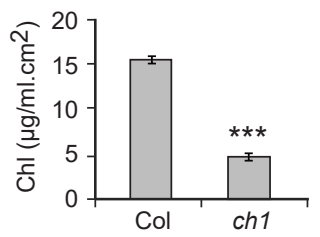

C

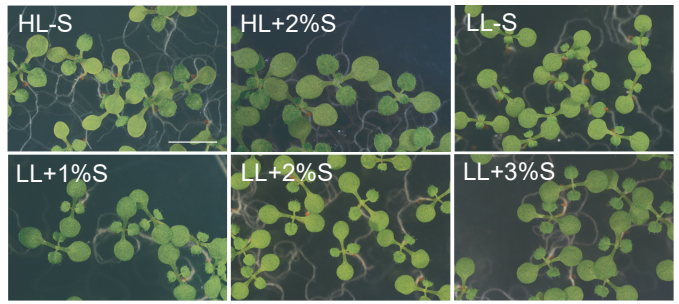

D

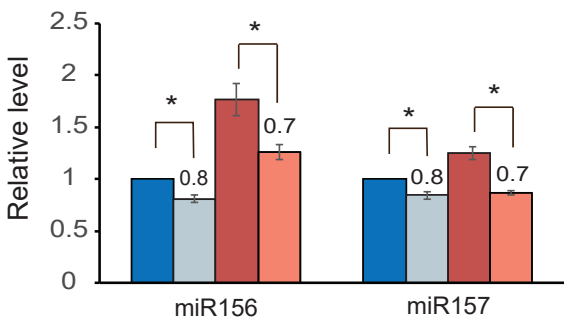

$\square \mathrm{HL}-\mathrm{S}$

$\square \mathrm{HL}+\mathrm{S}$

$\square$ LL -S

$\square \mathrm{LL}+\mathrm{S}$

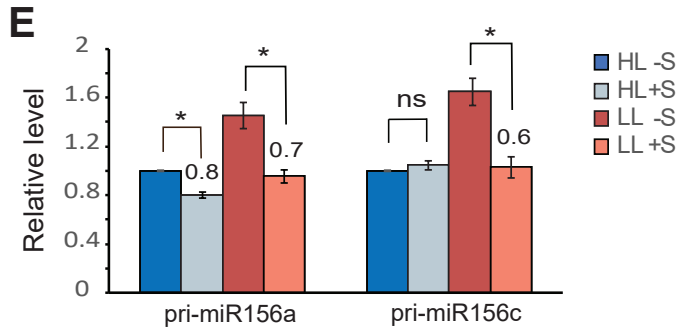




\section{Figure 4}

A

MIR156A

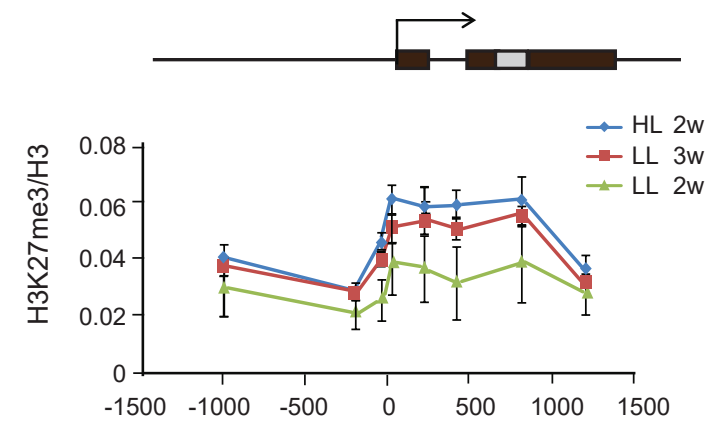

C

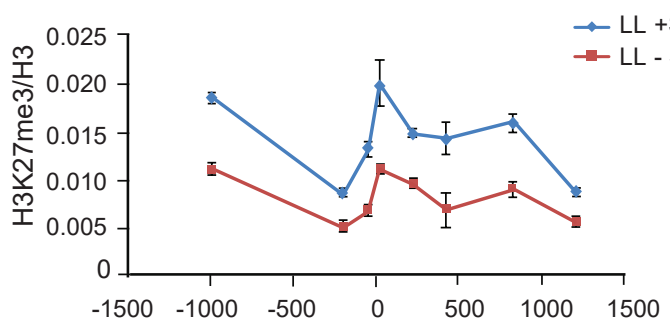

Position relative to transcription start site (nt)

E

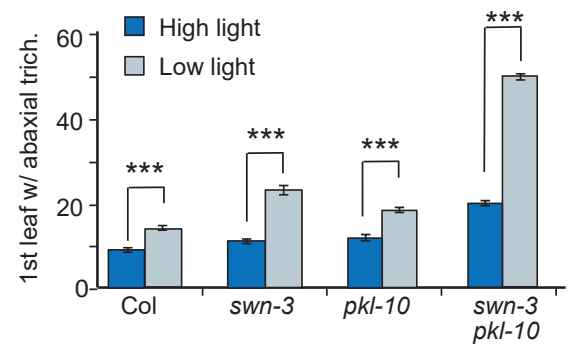

B

MIR156C
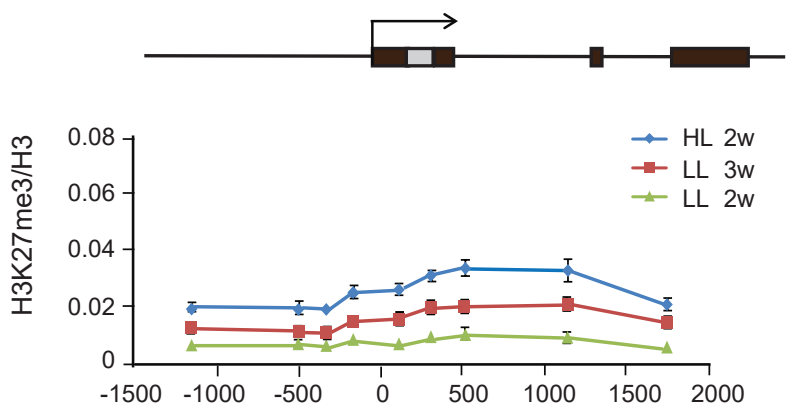

D

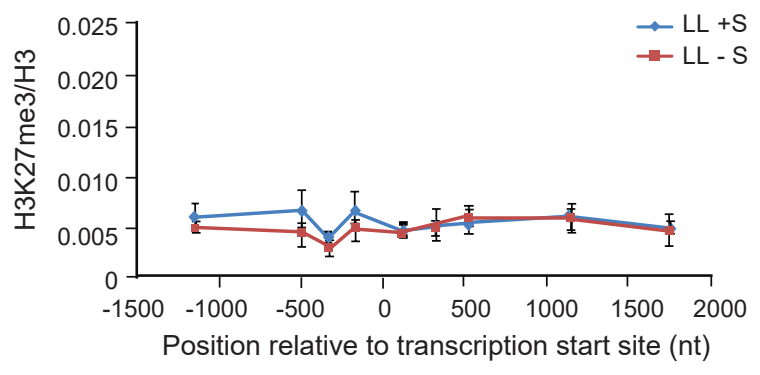

$\mathbf{F}$

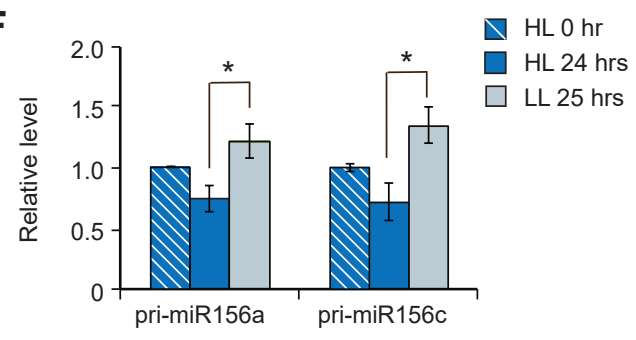




\section{Figure 5}

A

B

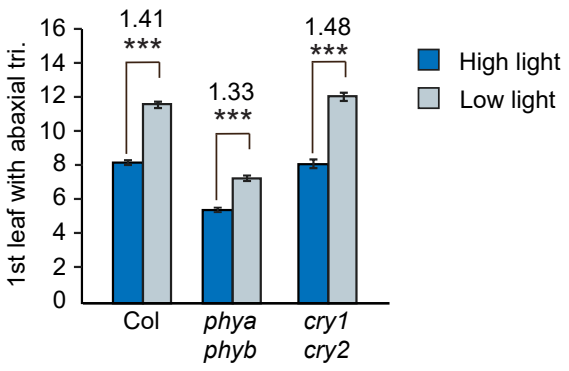

4D Light

$\begin{array}{cccc}+ & \mathrm{HL} & \mathrm{HL} & \mathrm{LL} \\ 2 \mathrm{D} \text { Dark } & \text { 1 week } & 2 \text { week } & \text { 3 week }\end{array}$
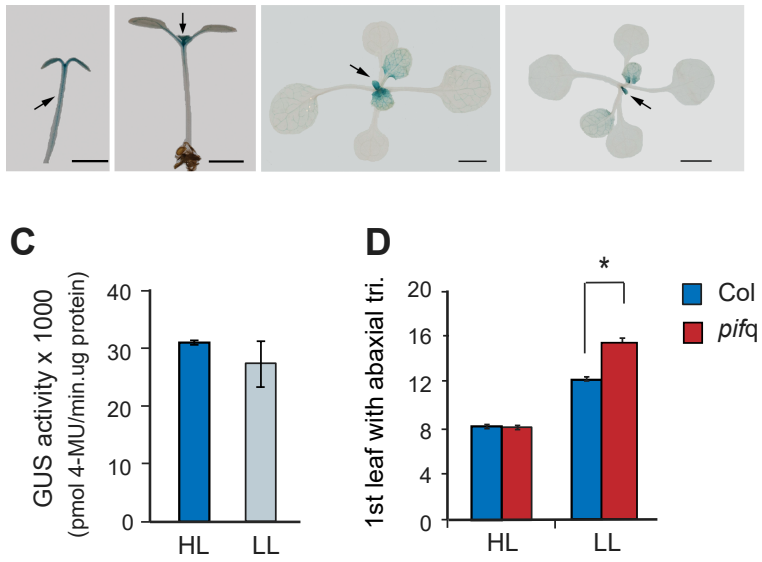


\section{Parsed Citations}

Angel A, Song J, Dean C, Howard M (2011) A Polycomb-based switch underlying quantitative epigenetic memory. Nature 476: 105-108 Google Scholar: Author Only Title Only Author and Title

Ballare CL, Pierik R (2017) The shade-avoidance syndrome: multiple signals and ecological consequences. Plant Cell Environ 40: 25302543

Google Scholar: Author Only Title Only Author and Title

Bauer H, Bauer U (1980) PHOTOSYNTHESIS IN LEAVES OF THE JUVENILE AND ADULT PHASE OF IVY (HEDERAHELIX). Physiologia Plantarum 49: 366-372

Google Scholar: Author Only Title Only Author and Title

Bouyer D, Roudier F, Heese M, Andersen ED, Gey D, Nowack MK, Goodrich J, Renou JP, Grini PE, Colot V, Schnittger A(2011)

Polycomb repressive complex 2 controls the embryo-to-seedling phase transition. PLoS Genet 7: e1002014

Google Scholar: Author Only Title Only Author and Title

Bouyer D, Roudier F, Heese M, Andersen ED, Gey D, Nowack MK, Goodrich J, Renou JP, Grini PE, Colot V, Schnittger A(2011)

Polycomb repressive complex 2 controls the embryo-to-seedling phase transition. PLoS genetics 7: e1002014

Google Scholar: Author Only Title Only Author and Title

Casal JJ (2013) Photoreceptor signaling networks in plant responses to shade. Annu Rev Plant Biol 64: 403-427

Google Scholar: Author Only Title Only Author and Title

Chory J (1997) Light modulation of vegetative development. Plant Cell 9: 1225-1234

Google Scholar: Author Only Title Only Author and Title

Chuck G, Cigan AM, Saeteurn K, Hake S (2007) The heterochronic maize mutant Corngrass1 results from overexpression of a tandem microRNA Nat Genet 39: 544-549

Google Scholar: Author Only Title Only Author and Title

Coustham V, Li P, Strange A, Lister C, Song J, Dean C (2012) Quantitative modulation of polycomb silencing underlies natural variation in vernalization. Science 337 : 584-587

Google Scholar: Author Only Title Only Author and Title

Day JS (1998) Light conditions and the evolution of heteroblasty (and the divaricate form) in New Zealand. New Zealand Journal of Ecology 22: 43-54

Google Scholar: Author Only Title Only Author and Title

Devlin PF, Halliday KJ, Harberd NP, Whitelam GC (1996) The rosette habit of Arabidopsis thaliana is dependent upon phytochrome action: novel phytochromes control internode elongation and flowering time. Plant $\mathrm{J}$ 10: 1127-1134

Google Scholar: Author Only Title Only Author and Title

Gou JY, Felippes FF, Liu CJ, Weigel D, Wang JW (2011) Negative regulation of anthocyanin biosynthesis in Arabidopsis by a miR156targeted SPL transcription factor. Plant Cell 23: 1512-1522

Google Scholar: Author Only Title Only Author and Title

He J, Xu M, Willmann MR, McCormick K, Hu T, Yang L, Starker CG, Voytas DF, Meyers BC, Poethig RS (2018) Threshold-dependent repression of SPL gene expression by miR156/miR157 controls vegetative phase change in Arabidopsis thaliana. PLoS Genet 14: e1007337

Google Scholar: Author Only Title Only Author and Title

Hennig L, Derkacheva M (2009) Diversity of Polycomb group complexes in plants: same rules, different players? Trends Genet 25: 414423

Google Scholar: Author Only Title Only Author and Title

Hennig L, Derkacheva M (2009) Diversity of Polycomb group complexes in plants: same rules, different players? Trends in genetics : TIG 25: 414-423

Google Scholar: Author Only Title Only Author and Title

Ito T, Sun B (2009) Epigenetic regulation of developmental timing in floral stem cells. Epigenetics : official journal of the DNA Methylation Society 4: 564-567

Google Scholar: Author Only Title Only Author and Title

Ito T, Sun B (2009) Epigenetic regulation of developmental timing in floral stem cells. Epigenetics 4: 564-567

Google Scholar: Author Only Title Only Author and Title

Jiang D, Wang Y, Wang Y, He Y (2008) Repression of FLOWERING LOCUS C and FLOWERING LOCUS T by the Arabidopsis Polycomb repressive complex 2 components. PLoS One 3: e3404

Google Scholar: Author Only Title Only Author and Title

Jones CS (1995) Does shade prolong juvenile development? Amorphological analysis of leaf shape changes in Cucurbita argyrosperma Subsp. Sororia (Cucurbitaceae). Amer. J. Bot. 82: 346-359 
Google Scholar: Author Only Title Only Author and Title

Jones CS (1999) An essay on juvenility, phase change, and heteroblasty in seed plants. Intl. J. Plant Sci. 160: S105-S111

Google Scholar: Author Only Title Only Author and Title

Kim JY, Oh JE, Noh YS, Noh B (2015) Epigenetic control of juvenile-to-adult phase transition by the Arabidopsis SAGA-like complex. Plant J 83: 537-545

Google Scholar: Author Only Title Only Author and Title

Lawrence EH, Springer CJ, Helliker BR, Poethig RS (2020) miR156-mediated changes in leaf composition lead to altered photosynthetic traits during vegetative phase change. New Phytol DOI: 10.1111/nph.17007

Google Scholar: Author Only Title Only Author and Title

Leivar P, Tepperman JM, Cohn MM, Monte E, A-Sady B, Erickson E, Quail PH (2012) Dynamic antagonism between phytochromes and PIF family basic helix-loop-helix factors induces selective reciprocal responses to light and shade in a rapidly responsive transcriptional network in Arabidopsis. Plant Cell 24: 1398-1419

Google Scholar: Author Only Title Only Author and Title

Li J, Wang Z, Hu Y, Cao Y, Ma L (2017) Polycomb Group Proteins RING1Aand RING1B Regulate the Vegetative Phase Transition in Arabidopsis. Front Plant Sci 8: 867

Google Scholar: Author Only Title Only Author and Title

Lusk CH (2004) Leaf area and growth of juvenile temperate evergreens in low light: species of contrasting shade tolerance change rank during ontogeny. Functional Ecology 18: 820-828

Google Scholar: Author Only Title Only Author and Title

Lusk CH, Falster DS, Jara-Vergara CK, Jimenez-Castillo M, Saldana-Mendoza A(2008) Ontogenetic variation in light requirements of juvenile rainforest evergreens. Functional Ecology 22: 454-459

Google Scholar: Author Only Title Only Author and Title

Mao YB, Liu YQ, Chen DY, Chen FY, Fang X, Hong GJ, Wang LJ, Wang JW, Chen XY (2017) Jasmonate response decay and defense metabolite accumulation contributes to age-regulated dynamics of plant insect resistance. Nat. Commnun 8: 13925

Google Scholar: Author Only Title Only Author and Title

Nguyen ST, Greaves T, McCurdy DW(2017) Heteroblastic Development of Transfer Cells Is Controlled by the microRNAmiR156/SPL Module. Plant Physiol 173: 1676-1691

Google Scholar: Author Only Title Only Author and Title

Njoku E (1956) Studies in the morphogenesis of leaves XI. The effect of light intensity on leaf shape in Ipomea caerulea. New Phytol. 55: $91-110$

Google Scholar: Author Only Title Only Author and Title

Nordhausen M (1912) Über Sonnen- und Schattenblåtter. II. . Ber dtsch bot Ges 30: 433-503

Google Scholar: Author Only Title Only Author and Title

Oster U, Tanaka R, Tanaka A, Rudiger W(2000) Cloning and functional expression of the gene encoding the key enzyme for chlorophyll b biosynthesis (CAO) from Arabidopsis thaliana. The Plant journal : for cell and molecular biology 21: 305-310

Google Scholar: Author Only Title Only Author and Title

Padmanabhan MS, Ma S, Burch-Smith TM, Czymmek K, Huijser P, Dinesh-Kumar SP (2013) Novel positive regulatory role for the SPL6 transcription factor in the N TIR-NB-LRR receptor-mediated plant innate immunity. PLoS Pathog 9: e1003235

Google Scholar: Author Only Title Only Author and Title

Pedmale UV, Huang SS, Zander M, Cole BJ, Hetzel J, Ljung K, Reis PA, Sridevi P, Nito K, Nery JR, Ecker JR, Chory J (2016)

Cryptochromes Interact Directly with PIFs to Control Plant Growth in Limiting Blue Light. Cell 164: 233-245

Google Scholar: Author Only Title Only Author and Title

Pico S, Ortiz-Marchena MI, Merini W, Calonje M (2015) Deciphering the Role of POLYCOMB REPRESSIVE COMPLEX1 Variants in Regulating the Acquisition of Flowering Competence in Arabidopsis. Plant Physiol 168: 1286-1297

Google Scholar: Author Only Title Only Author and Title

Reed JW, Nagatani A, Elich TD, Fagan M, Chory J (1994) Phytochrome Aand Phytochrome B Have Overlapping but Distinct Functions in Arabidopsis Development. Plant Physiol 104: 1139-1149

Google Scholar: Author Only Title Only Author and Title

Rhoades MW, Reinhart BJ, Lim LP, Burge CB, Bartel B, Bartel DP (2002) Prediction of plant microRNAtargets. Cell 110: $513-520$ Google Scholar: Author Only Title Only Author and Title

Roig-Villanova I, Martinez-Garcia JF (2016) Plant Responses to Vegetation Proximity: AWhole Life Avoiding Shade. Front Plant Sci 7: 236

Google Scholar: Author Only Title Only Author and Title

Schramm R (1912) Über die anatomischen Jugenformen der Blåtter einhheimischer Holzpflanzen. Flora (Jena) 104: 225-295

Google Scholar: Author Only Title Only Author and Title 
Schwarz S, Grande AV, Bujdoso N, Saedler H, Huijser P (2008) The microRNA regulated SBP-box genes SPL9 and SPL15 control shoot maturation in Arabidopsis. Plant Mol Biol 67: 183-195

Google Scholar: Author Only Title Only Author and Title

Shu J, Chen C, Thapa RK, Bian S, Nguyen V, Yu K, Yuan ZC, Liu J, Kohalmi SE, Li C, Cui Y (2019) Genome-wide occupancy of histone H3K27 methyltransferases CURLY LEAF and SWNGER in Arabidopsis seedlings. Plant Direct 3: e00100

Google Scholar: Author Only Title Only Author and Title

Smith H (1982) Llght quality, photoperception, and plant strategy. Ann Rev Plant Physiol 33: 481-518

Google Scholar: Author Only Title Only Author and Title

Stief A, Altmann S, Hoffmann K, Pant BD, Scheible WR, Baurle I (2014) Arabidopsis miR156 Regulates Tolerance to Recurring Environmental Stress through SPL Transcription Factors. Plant Cell 26: 1792-1807

Google Scholar: Author Only Title Only Author and Title

Valladares F, Niinemets U (2008) Shade tolerance, a key plant feature of complex nature and consequences. Ann Rev Ecol Syst 39: 237257

Google Scholar: Author Only Title Only Author and Title

Wang J-W, Czech B, Weigel D (2009) miR156-regulated SPL transcription factors define an endogenous flowering pathway in Arabidopsis thaliana. Cell 138: 738-749

Google Scholar: Author Only Title Only Author and Title

Wu G, Park MY, Conway SR, Wang JW, Weigel D, Poethig RS (2009) The sequential action of miR156 and miR172 regulates developmental timing in Arabidopsis. Cell 138: 750-759

Google Scholar: Author Only Title Only Author and Title

Wu G, Poethig RS (2006) Temporal regulation of shoot development in Arabidopsis thaliana by miR156 and its target SPL3.

Development 133: 3539-3547

Google Scholar: Author Only Title Only Author and Title

Xie Y, Liu Y, Wang H, Ma X, Wang B, Wu G, Wang H (2017) Phytochrome-interacting factors directly suppress MIR156 expression to enhance shade-avoidance syndrome in Arabidopsis. Nat Commun 8: 348

Google Scholar: Author Only Title Only Author and Title

Xu M, Hu T, Smith MR, Poethig RS (2016) Epigenetic Regulation of Vegetative Phase Change in Arabidopsis. Plant Cell 28: 28-41

Google Scholar: Author Only Title Only Author and Title

Xu M, Hu T, Zhao J, Park MY, Earley KW, Wu G, Yang L, Poethig RS (2016) Developmental Functions of miR156-Regulated SQUAMOSA PROMOTER BINDING PROTEIN-LIKE (SPL) Genes in Arabidopsis thaliana. PLoS Genet 12: e1006263

Google Scholar: Author Only Title Only Author and Title

Xu M, Leichty AR, Hu T, Poethig RS (2018) H2AZ promotes the transcription of MIR156Aand MIR156C in Arabidopsis by facilitating the deposition of H3K4me3. Development 145

Google Scholar: Author Only Title Only Author and Title

Xu SL, Chalkley RJ, Maynard JC, Wang W, Ni W, Jiang X, Shin K, Cheng L, Savage D, Huhmer AF, Burlingame AL, Wang ZY (2017) Proteomic analysis reveals O-GIcNAc modification on proteins with key regulatory functions in Arabidopsis. Proc Natl Acad Sci U S A 114: E1536-E1543

Google Scholar: Author Only Title Only Author and Title

Xu Y, Guo C, Zhou B, Li C, Wang H, Zheng B, Ding H, Zhu Z, Peragine A, Cui Y, Poethig S, Wu G (2016) Regulation of Vegetative Phase Change by SW2/SNF2 Chromatin Remodeling ATPase BRAHMA Plant Physiol 172: 2416-2428

Google Scholar: Author Only Title Only Author and Title

Yamaguchi A, Wu MF, Yang L, Wu G, Poethig RS, Wagner D (2009) The microRNAregulated SBP-Box transcription factor SPL3 is a direct upstream activator of LEAFY, FRUITFULL, and APETALA1. Dev Cell 17: 268-278

Google Scholar: Author Only Title Only Author and Title

Yang H, Howard M, Dean C (2014) Antagonistic roles for H3K36me3 and H3K27me3 in the cold-induced epigenetic switch at Arabidopsis FLC. Curr Biol 24: 1793-1797

Google Scholar: Author Only Title Only Author and Title

Yang L, Conway SR, Poethig RS (2011) Vegetative phase change is mediated by a leaf-derived signal that represses the transcription of miR156. Development 138: 245-249

Google Scholar: Author Only Title Only Author and Title

Yang L, Xu M, Koo Y, He J, Poethig RS (2013) Sugar promotes vegetative phase change in Arabidopsis thaliana by repressing the expression of MIR156A and MIR156C. eLife 2: e00260

Google Scholar: Author Only Title Only Author and Title

Yu N, Cai WJ, Wang S, Shan CM, Wang LJ, Chen XY (2010) Temporal control of trichome distribution by microRNA156-targeted SPL genes in Arabidopsis thaliana. Plant Cell 22: 2322-2335 
Google Scholar: Author Only Title Only Author and Title

Yu S, Cao L, Zhou CM, Zhang TQ, Lian H, Sun Y, Wu J, Huang J, Wang G, Wang JW (2013) Sugar is an endogenous cue for juvenile-toadult phase transition in plants. eLife 2: 000269

Google Scholar: Author Only Title Only Author and Title

Zhang H, Bishop B, Ringenberg W, Muir WM, Ogas J (2012) The CHD3 remodeler PICKLE associates with genes enriched for trimethylation of histone H3 lysine 27. Plant physiology 159: 418-432

Google Scholar: Author Only Title Only Author and Title

Zhang H, Rider SD, Jr., Henderson JT, Fountain M, Chuang K, Kandachar V, Simons A, Edenberg HJ, Romero-Severson J, Muir WM, Ogas J (2008) The CHD3 remodeler PICKLE promotes trimethylation of histone H3 lysine 27. J Biol Chem 283: 22637-22648

Google Scholar: Author Only Title Only Author and Title

Zhang TQ, Lian H, Tang H, Dolezal K, Zhou CM, Yu S, Chen JH, Chen Q, Liu H, Ljung K, Wang JW (2015) An intrinsic microRNAtimer regulates progressive decline in shoot regenerative capacity in plants. Plant Cell 27: 349-360

Google Scholar: Author Only Title Only Author and Title

Zhou Y, Wang Y, Krause K, Yang T, Dongus JA, Zhang Y, Turck F (2018) Telobox motifs recruit CLF/SWN-PRC2 for H3K27me3 deposition via TRB factors in Arabidopsis. Nat Genet 50: 638-644

Google Scholar: Author Only Title Only Author and Title 